\title{
Guardian farmers and the selection of creole varieties of onions
}

\section{Opinion}

Selecting, forging, genetically improving their traditional varieties is a process inherent to seed-guarding farmers. These farmers maintain their native varieties throughout successive generations. We find in São José do Norte, a small municipality located on a narrow strip of land between Laguna dos Patos and the Atlantic Ocean, which is located in the State of Rio Grande do Sul, in the extreme south of Brazil, a family of farmers who they have selected their onion variety since 1952 . A process that has been improved over the years, but which is also passed on between successive generations through dialogue, narratives, imitations.

São José do Norte was already considered the largest producer of onions in Brazil, as well as its onion obtained in 1920, in an agricultural festival held in Spain, the title of best onion in the world. The quality and productivity of São José do Norte onions provided this prominent place on the national scene.

At a time when there was no formal seed trade, producing their own seeds was a vital necessity for these farmers, thus, through a mass selection of bulbs, local farmers selected creole varieties of onions that phenotypically expressed their relative perceptions. to an excellent variety of onions. In this way they forged the pear, northern and Creole varieties.

The mass selection of the bulbs was aided by the commercialization process that was done in strips, a cluster of 25 bulbs arranged in a braid. To make the braid, all the onions produced by a farming family passed through the hands of the farmers and in this way promulgated a great pressure of selection, since it was during the making of the ridge that many farmers removed the best specimens of onions that would become part of the process. number of bulbs for seed production.

Mr. Wilson Pinheiro's family proceeded with the selection process differently. In addition to selecting the bulbs during the making of the string, Mr. Wilson also selected his variety in the production, bulb and seed crops. He excluded the sickest, the least developed, and what he judged to be outside the standard of their variety. In addition, Mr. Wilson showed his children how, when and why to select certain characteristics.

Over the years, the practice previously narrated had been displaced. Local farmers started to acquire their seeds in the local market, which offers seeds from other producers and research institutions that are genetically improved in other regions of Brazil. This process led to the genetic erosion of the traditional varieties of onions from São José do Norte and fertilized the loss of the quality of their onions due to the use of cultivars that are not adapted to the soil conditions, climate of the local environment.

Contrary to this process, Mr. Wilson kept his onion variety and forged in his children's memory the characteristics that they should select in order to obtain a perfect example of onion. The father showed each son what an ideal onion should look like, with each son
Volume 5 Issue 3 - 202I

\author{
Régis de Araujo Pinheiro \\ Eng. Agr. Msc. Family Agricultural Production Systems, Federal \\ University of Pelotas, Brazil
}

Correspondence: Régis de Araujo Pinheiro, Eng. Agr. Msc. Family Agricultural Production Systems, Federal University of Pelotas, Brazil, Email regispinheiroagro@gmail.com

Received: April 28, 2021 | Published: May 18, 2021

responsible for selecting a portion of the selected bulbs. After carrying out this process, Mr. Wilson performed a new selection together with each son, showing and asking why he selected such characteristics found in that bulb, that is, when he passed on to each of the children, the father gestated, fixed and confronted the knowledge, perceptions and intuitions in and with each one. Subsequently, the bulbs were stored, and during the planting season a new selection was made, so that only onions of extreme quality could compose the squad of the seed production crop.

In this respect, we can say that whoever produces a Creole seed produces a seed filled with stories, stories of life and that intertwine, that is, it is impossible to tell the family story without telling the story of the Creole variety and vice versa. In addition, the act of conserving and sharing Creole seeds can be characterized in the transmission of a meme, or a symbolism, according to Dawkins' thinking. Wilson were transmitted through the narratives to his children and wife, which they passed on, during the research conversations to us.

Culture is characterized by being non-genetic information, and when we think that the units of culture are transmitted not only between generations but also within each generation, since in the processes of exchanging ideas there is a confluence of influences, that is to say the thoughts of the parents.

\section{Funding}

None.

\section{Acknowledgments}

None.

\section{Conflicts of interest}

The authors declare no conflict of interest. 